\title{
Festival Heterotopias: Spatial and Temporal Transformations in Two Small-Scale Settlements
}

\author{
Bernadette Quinn \\ Technological University Dublin, bernadette.quinn@tudublin.ie \\ Linda Wilks \\ Open University, lindajwilks@yahoo.co.uk
}

Follow this and additional works at: https://arrow.tudublin.ie/tfschhmtart

Part of the Human Geography Commons, Leisure Studies Commons, and the Rural Sociology Commons

\section{Recommended Citation}

Quinn, B. \& Wilks, L, (2017) Festival heterotopias: spatial and temporal transformations in two small-scale settlements. Journal of Rural Studies, Volume 53, Pages 35-44, DOI: 10.1016/j.jrurstud.2017.05.006

This Article is brought to you for free and open access by the School of Tourism \& Hospitality Management at ARROW@TU Dublin. It has been accepted for inclusion in Articles by an authorized administrator of ARROW@TU Dublin. For more information, please contact arrow.admin@tudublin.ie, aisling.coyne@tudublin.ie, gerard.connolly@tudublin.ie.

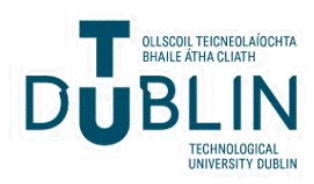


Quinn, B. \& Wilks, L, (2017) Festival heterotopias: spatial and temporal transformations in two small-scale settlements. Journal of Rural Studies, Volume 53, Pages 35-44

\section{Abstract}

This paper reports the findings of research undertaken at two festivals which take place in small-scale settlements: one in a village set in rural western Ireland, the other in a small coastal town set within a largely rural Area of Outstanding Natural Beauty in southern England. It uses Foucault's concept of heterotopia as an analytical tool to further understandings of how the spatial and temporal interruptions caused by festivals temporarily transform the prevailing social order. The findings attest to the manner in which festivals juxtapose several incompatible spaces, creating a diverse array of social alterations in consequence, and highlight the accumulative effect produced through the transformation of multiple discrete spaces. They empirically illustrate the well-established argument that heterotopias disrupt traditional concepts of time and further support their temporal layering effect: that is, the sense of past festivals intertwining with and informing the social actors' experience of current festivals. While the findings illustrate how festivals can require certain acts or rituals to gain entry, importantly, they show how maintaining these rituals during the festival is critical to social actors' continued immersion in this temporary world. The study concludes by offering a modified set of principles of heterotopia specifically tailored to apply to festivals within the context of rural settlements.

Keywords: Festivals; Heterotopia; Social order; Time; Space; Rural 


\section{Introduction}

Recent research on festivals in the social sciences has been strongly preoccupied with festivals held in large urban areas (e.g. Johansson and Kociatkiewicz, 2011; Olsen, 2012; Stevens and Shin, 2012), to the neglect of festivals which take place in rural settlements. However, Gibson et al (2011) highlight the special and exceptional importance of festivals to rural communities, emphasising their transformative effect, as well as their role in reflecting the collective identities of place and people. Duffy and Waitt (2011) similarly stress the significance of rural festivals to communities. While Gibson et al (2011) note that the scale of festivals in rural areas of Australia varies, studies of the Parkes Elvis Festival demonstrate how a small, remote town can attract large numbers of visitors (Brennan-Horley et al, 2007; Connell and Gibson, 2011). In addition, as Rihova (2013: 119) suggests, the prevalent focus on hard-nosed economic impacts within the event tourism discourse has meant that, until recently, developing an understanding of the social and cultural aspects of festivals in regional contexts has been somewhat neglected. This paper aims to redress these imbalances in the literature by seeking to understand how the spatial and temporal interruptions caused by two festivals temporarily transform the social order within two small-scale settlements. The two festivals studied, one in a village set in rural western Ireland, the other in a small coastal town set within a largely rural Area of Outstanding Natural Beauty in southern England, celebrate folk music. While the links between folk music and rurality have been studied (Yarwood and Charlton, 2009; Nettl et al. 1992), folk music festivals have received much less attention, and this discrepancy is also addressed here.

To date, a wealth of concepts and theories around space and time, including rites and rituals, liminality and the carnivalesque have been used to try to understand the social role played by festivals. Historically, time was privileged as an avenue of enquiry, but the importance of space has become increasingly recognised with Hetherington (1997: ix), for instance, arguing that modernity should be understood not just as a social ordering but as a social and spatial ordering. However, thus far, while the literature has grown rapidly, and while the wealth of perspectives being brought to the topic has 
yielded significant insight, it could be argued that the body of work on the ways in which festival space and time affects social order lacks coherency. This paper proposes that Foucault's heterotopia, a concept which has been under-utilised in the festival studies literature to date, might usefully provide the basis of a coherent and synthesizing theoretical framework.

For Foucault (1986: 24), heterotopic sites are ones in which all the other real sites within a culture are simultaneously represented, contested and inverted: the role of the heterotopic site is to 'suspect, neutralize or invert the set of relations that they happen to designate, mirror or reflect'. Although Foucault himself did not fully develop the concept (Johnson, 2013), it has been taken up by others, including by a few researchers investigating festivals. It is advocated as an analytical tool here because it seems at once to encompass several of the spatial and temporal concepts often singularly used to interpret the social function of festivals. It therefore promises a comprehensive perspective because it is concerned with the quality of festival space as well as with festival time. As Foucault himself provided only a starting point for the theory, there is much potential for further development.

Thus, this paper conceives of festivals as heterotopia. The aim of this study is to highlight the usefulness of a heterotopic framework for studying festivals in rural contexts and to elaborate and build on earlier applications of the concept.

\subsection{The transformative potential of festivals}

The idea that festivals possess a transformative quality is widely accepted by social scientists and has been investigated by researchers approaching the topic from a variety of theoretical angles. Time, space and social relations are understood to be visibly and affectively transformed through the workings of a festival.

Taking a temporal approach, many social scientists have emphasised the fact that festivals serve to interrupt and offer a temporary release from the strictures and regulations of daily time (Bakhtin, 1968). During this 'time out of time', a series of rituals are enacted through which the core values 
commonly prized by a community are celebrated. Inversion, distortion and a powerful denial of the established social order are understood to be central to the social drama enacted during festival time (Duvignaud, 1976). Falassi (1987) highlights a series of rituals that characterise festivals: from the valorisation ritual at the outset which sees the official claiming and alteration of ordinary space into festival space through, for example, road closures, cessation or curtailment of routine activities, the erection of signage and bunting, and so on; through a series of rites of reversal where space, people and time assume characteristics that may be the polar opposite of their normal roles; as well as further rites of exchange, conspicuous display, conspicuous consumption and competition. Falassi (1987) also points to the rites of passage that can characterise festivals. Drawing on Van Gennep (1960), Turner (1982a: 121) comments that in the 'betwixt and between', liminal, or middle phase of rites of passage, people 'play' with the elements of the familiar, leading to de-familiarisation. As in Bakhtin's carnival time, a series of subversive and playful events may occur. Myths, symbols and works of art may be generated or channeled by this liminal space-time, according to Turner, providing people with a set of models or paradigms which, at one level, enable short-term reclassifications of social experience.

Using ritual as an analytical lens to understand the social meaning of festivals leads to a further uncovering of the complexities of the phenomenon. Through his discussions of liminality, Turner (1982a: 50) connects festivals to the idea of communitas, which he describes as an 'alternative and more liberated way to be socially human'. For Falassi (1987), communitas emerges through the rites of exchange effected through festival activity, as realising equality among community members is a central part of the exchange process. Turner (1982a) explains that the inclusivity of communitas contrasts with the exclusionary tendencies of the social structures that give sense and order to everyday life. However, Turner (1982a: 84) warns of the potentially perilous nature of the 'liminal space-time "pod" created by ritual', precisely because of this liberation of the social structure. Turner's warning is a reminder of a central theme running through all of this literature: that while the activities, behaviours and practices that characterise festival time exude a collective playfulness, exuberance, equality and sense of escape from daily routine, they are ultimately grounded in the basic structures 
and systems of ordinary social life. Undoubtedly then, festival time provides a contrast to ordinary time and according to Abrahams (1982), the self is playfully distorted and life is stretched to its fullest through excess in the high time of the festival.

Drawn out very clearly in Bakhtin's (1968) work on the closely associated form of carnival, festivals have been viewed as spaces of potential resistance where people are momentarily permitted to invert social norms and to turn the world 'upside down'. Alternatively, other researchers, like Eagleton (1981), see festival time as one that remains complicit with authority, by virtue of the fact that it is 'a licensed affair' functioning as 'a permissible rupture of hegemony'. Viewed as such it offers no societal threat, but rather functions as a support, facilitating a temporally bounded release of energies, but safeguarding societal interest in the long-term. Falassi (1987: 3) combines these perspectives, arguing that they are not mutually exclusive and that festivals cannot be effected simply through distortion, inversion and role-reversal behaviour alone. Rather, echoing Turner (1982a), he argues that they demand 'the simultaneous presence ... of all the basic behavioural modalities of daily social life' albeit all modified, 'by distortion, inversion, stylization or disguise in such a way that they take on an especially meaningful character'.

In all of the work discussed above, temporal approaches to understanding festivals prevail. In parallel, however, another body of work has tackled the issue from the perspective of space. Jackson (1988), in a study of London's Notting Hill carnival was one of the earliest geographers to write about festivals and space. Since then, the literature has bourgeoned, particularly in very recent years, with a particular focus on festivals and other kinds of events taking place in cities (Johansson and Kociatkiewicz, 2011; Pløger, 2010; Quinn, 2005; Waterman, 1998). Here, events are understood to be at once positioned in time and space, yet connected into much wider social and material networks and flows of interactivity (Weller, 2013). Falconi (2014), for example, has explained it in terms of an 'immobile festival structure', rooted in, or at least reflective of, place, and a set of fluid, mobile and dynamic performances and activities which become incorporated into the festival structure. By negotiating the 
dynamic and contested politics of the particular host place, they become incorporated into the festival, which in the making, may revise collective memories, attach new meanings to cultural practices and revalue the symbolic capital of the city (Weller, 2013: 2855). While the literature has long been conscious that the transformation of space is always open to contestation, and sometimes associated with displacement, it is generally accepted that while 'city space imbues the festival with meaning, [but] the process is reciprocal because the festival provides new meanings for the city it inhabits' (Johansson and Kociatkiewicz, 2011). Gallup (1988: xii), in a study of the Salzburg Festival even went so far as to ask whether the festival landscape is the 'normal' or 'ordinary' landscape, while for the remainder of the year, the place itself is simply preparing for 'the event'. Spatial transformations are effected as festivals take over districts and sometimes entire cities, altering routine mobilities, the regular uses of spaces and their habitual appearances, as well as affecting the ambiance of the everyday in the process (Johansson and Kociatkiewicz (2011). Lefebvre's (1991) ideas about the production of space have often underpinned interpretations of how festivals, and events more generally, act to reproduce the city. In effecting these transformations, it has been argued that festivals can be interpreted as creating an atmosphere of potentials (Pløger, 2010: 853), or to possess what (Shields, 2003: 3) called `an open, creative potentiality’.

A small number of researchers have studied how festivals transform rural places. Gibson and Davidson (2004) looked at how a small Australian town, Tamworth, has been reshaped by an annual Country and Western Music Festival. The authors suggest that rather than being short-term transformations, the changes stimulated by this festival have been long-term, having a major effect on place marketing. Also drawing on an Australian case study, Curtis (2011) suggests that the impact of the Jazz Festival held in the otherwise little-known country town of Wangaratta transforms the town for four days of music in an intense, uninterrupted and physically appealing environment and is said to be important in terms of community building. Similarly, Rofe and Winchester (2011) highlight the temporary transformation of rural places from spaces of agricultural production to landscapes of festival-led economic consumption. 
Several researchers have investigated how folk music, and popular culture more generally, can strongly inform constructions of rurality. Smith (1997) noted how places can be strongly associated with, and sometimes represented by, particular styles of music; Kong (1995) commented on how music can be studied to gain insight into the character and identity of places, as well as into the attachments that individuals and groups develop to places (Yarwood \& Charlton 2009). Yet, beyond the studies cited above, there is little published on the transformative potential of festivals in rural areas.

\section{Theory}

The literature discussed in the previous section has been formative in shaping interpretations of the relationship of festival space and time to the social order and is widely cited. However, as argued earlier, a shortcoming of this work is that it lacks an over-arching theoretical framework both to adequately encase the diverse concepts employed and to facilitate an appreciation of the inter-twining roles of time and space. Accordingly, Foucault's concept of heterotopia, a largely overlooked theoretical idea which shows promise for further development within this context, will next be considered.

\subsection{The concept of heterotopia}

Foucault's concept of heterotopia was first outlined in a 1966 radio lecture, 'Des espaces autres', and then as a lecture with similar content to a group of architects in 1967, the transcribed text of which was approved by Foucault and published in 1984 (Foucault, 1984). Several English translations have also been published posthumously (Foucault, 1986, 1997, 2008; Foucault and Miskowiec, 1986). In his talks, Foucault introduced the idea of a heterotopia, what he described as a 'counter-site': 'a kind of effectively enacted utopia in which the real sites, all the other real sites that can be found within the culture are simultaneously represented, contested and inverted' (Foucault and Miskowiec, 1986: 24). Foucault uses the term 'emplacement', rather than the more common term of place, a technical term which Dehaene et al (2008: 23-4) suggests should be retained in further discussion in order to effect 
both emphasis and estrangement. He argued that in contrast to utopias, heterotopias are located in real, physical, space-time, and serve to temporarily introduce different ways of ordering society and space in particular places, at particular times. Foucault went on to explain that six principles underpin the idea of heterotopia: (1) all cultures constitute heterotopias, although in varied forms, (2) their function can change over time, (3) they juxtapose several incompatible sites within a single real place, (4) they break or disrupt traditional concepts of time, (5) they may require certain acts, performances or rituals to gain entry to them, and (6) they exist only in relation to all other sites and spaces.

Foucault did little to develop the concept beyond the talks, and for this reason, heterotopia as an idea has attracted much criticism over the years for being incomplete, inconsistent and even incoherent (Quang et al., 2013). For Johnson (2013: 790), Foucault's treatment of heterotopia is 'sketchy, openended and ambiguous' and yet as he suggests, the idea's 'fragmentary and elusive quality' may be the very reason that it has been taken up and interpreted by so many researchers in so many disciplines, from literary studies to architecture and sociology. For many, the value of using heterotopia as an analytical tool lies in interrogating and making sense of the difference that emerges in space-time (Saldanha, 2008). The counter-site nature of heterotopia affords a glimpse into the workings of mainstream society from an exterior, yet connected viewpoint. For Hetherington (1997: 40), heterotopias are spaces where 'an alternative social ordering is performed', in contrast to 'the takenfor-granted mundane idea of social order that exists within society'.

For those interested in understanding the transformations that festivals bring to their host societies, the concept of heterotopia instinctively seems to have obvious merit. The starting principle, that all cultures possess heterotopias, recalls Turner's (1982b: 11) assertion that 'people in all cultures recognise the need to set aside certain times and spaces for community creativity and celebration'. Intuitively, the second principle, that heterotopias function differently as societies evolve, also holds for festivals. Over time, as societies have evolved, the nature, timing, location and scale of festivals has changed accordingly. As globalization has progressed and economic competition for highly mobile 
flows of capital, creativity, labor and consumers has heightened, societal expectations of the value and function of festivals has altered. However, while Foucault's first two principles certainly have application for festival studies, their emphases on the macro scale requires a more longitudinal line of enquiry and for this reason are not considered in the study reported here. Among the four remaining principles, the third and fourth are particularly evocative of festivals. The third principle, dealing with the juxtaposition of several, sometimes incompatible, spaces in one single real place, strongly recalls the festival. Bringing together ideas and performers from multiple backgrounds, staging events and performances in unorthodox spaces routinely used for other purposes is standard practice in festival production. Festivals are specifically mentioned by Foucault in respect of the fourth principle, which holds that heterotopias are most often linked to slices in time, and constitute a break from ordinary time. He spoke about 'heterotopias of indefinitely accumulating time' e.g. museums and libraries, where information, ideas and memories of multiple different time periods are stored together in one place and at one time. In contrast, he also depicted heterotopias as 'time in its most fleeting, transitory, precarious aspect' (Foucault and Miskowiec, 1986: 26), using the example of transitory festival time. This is the only instance where Foucault specifically cites festivals as examples of heterotopias, but as other researchers have applied the concept of heterotopia to different festivals, the relevance of other principles has become more apparent.

\subsection{Festivals and heterotopia}

A handful of festival researchers have turned to the concept, although only quite recently. Strong similarities bind these studies, one of the earliest of which is that of Karaosmanoglu (2010) who examined Ramadan festivities in Istanbul. Her interpretation of the concept emphasises both temporal and spatial dimensions. She writes about the disruptive force of Ramadam festivities in breaking down the usual divisive relationships and promoting instead peace and tolerance across groups of people irrespective of demographics or background. Implicitly referencing the fourth heterotopian 'slices of time' principle, the disruptive effect of the festivities is said to promote a 
different social order, where public life functions differently in the flowing time of the festival and a new form of social ordering is constructed in festive spaces. Karaosmanoglu also picks up on Foucault's ideas of heterotopia as accumulated time, linking the concept of utopia to a nostalgia for a mythical Ottoman time in the past.

The sense of layered time which Karaosmanoglu describes, with idealised memories of past festivities, is further elaborated by Howell (2013). She also highlights temporal aspects in her account of the ritualised Badalisc Festival of Northern Italy. Placing Foucault's heterotopia alongside Turner's (1982a) work on ritual, liminality and communitas, Howell highlights how the festival, as an 'other place' ( $p$. 46) can force people to step outside their everyday mundane patterns of 'normalcy'. She concludes that this 'time-out-of-mundane-time' (p. 60) provides the ambience and opportunity for communication which can enhance community bonds. She also points to ways in which a sense of liminality generated through the festival allows other times and influences to 'bubble up' into the present (p. 53), thus ensuring that festivals embody both time and place, encouraging a remembrance, a re-working and a continued celebration of people, moments and traditions.

Also linking Foucault's heterotopia to Turner's and Bakhtin's theories in his study of Confest, an Australian alternative lifestyle event, St John (2001) suggests that temporary event-spaces are often liminal realms. St John calls these spaces of 'otherness', or 'counter-sites' as he notes that Foucault terms them, 'alternative cultural heterotopias' (p. 51). St John outlines the interdependent spatial characteristics which he sees as separating alternative cultural heterotopias from adjacent sites: resistance, otherness, heterogeneous zones and contested spaces. He also draws on Maffesoli's (1996) concept of neo-tribes to highlight the geographically juxtaposed but competing sets of discourses and practices in evidence at the festival. Whilst not providing any further development of Foucault's concept of heterotopia, St John's acknowledgement of its relevance to festival studies, and its links to Turner's and Bakhtin's theories is helpful. Of further note is St John's suggestion that a festival may be a collection of heterotopias, rather than a single coherent heterotopia. 
Further emphasis on the 'other spaces' aspect of Foucault's (2008) heterotopia, can be seen in Yazbak's (2011) paper on the historic festival of Nabi Rubin, which was first held in the thirteenth century in Palestine, ending in 1946. Yazbak explicitly uses heterotopia as a concept to explain how the festival created a transitory counter-space, where life was extraordinary and normal social ordering was altered. At Nabi Rubin, people 'escaped' to a simpler life. Relative to ordinary time, the festival was characterised by more intense and more diverse social interaction, and a loosening of the customary segregation of the sexes. Entry into, and participation in, the festival as heterotopia was marked by a clear set of rituals and Yazbak explained how the contrast between the normal social order and that prevailing in the transitory festival world permitted the festival site to function as a mirror image of the permanent city.

While spatial transformations are treated in all the above, Falconi's (2014: 186), application of the concept of heterotopia to two Latin American festivals, specifically illustrates the third principle, that heterotopias juxtapose several spaces in one real place. As he sees it, 'the festival structure is immobile, while the contents, that is, the performances and activities that are set in this kind of vessel, are mobile and dynamic'. While arguably under-playing the ability of individual places to distinguish the festivals that they host, Falconi clearly articulates the facility that festivals have to accumulate influences and inputs from many different places. Viewed as such, the analytical value of heterotopia becomes apparent, as it can illustrate the potentially tense relationships between the different places shaping the festival and the different spaces through which the festival is produced.

Stanciu (2014), meanwhile, in a study of a Danish LGBTQ film festival, MIX Odense, highlights how festivals appear as heterotopias: playing 'in the dichotomy of here and there'; 'being an enclosed space' and presuming acts of access and exclusion where purely physical admission does not necessarily mean a full sense of identification with the festival community; being a tool of 'othering', subverting, or challenging norms and established meanings; and acting as an instrument of selfreflection or mirroring so that subjectivity may be constructed or interrogated. Stanciu's interpretation 
emphasises the spatial reading afforded by Foucault's heterotopia, however, she also focuses on the social relations fostered through the festival and highlights how the spaces of the film festival manage to foster community in spite of apparent discordance.

Very recently, Wilks and Quinn (2016) have linked social capital and cultural capital to heterotopia within the context of festivals. Their approach enables a detailed exploration of how social relations are affected, shedding light on how bonding and bridging social capital are formed in the process and on how cultural capital is involved.

\section{Methods}

This study follows those reviewed in its use of heterotopia. Empirically it investigates two festivals, the Feakle Traditional Music Festival, held in Feakle, a tiny village in a rural part of County Clare in Western Ireland, and the Sidmouth International Folk Week, held in Sidmouth, a small coastal town located on the south coast of England at the mouth of the river Sid, bounded by hills to the west and east and set within a largely rural Area of Outstanding Natural Beauty. These were selected because they effectively dominate the small-town / rural environs while they are taking place. In addition, they were well matched in both being folk arts focused; long-standing annual events (Sidmouth in its 60th year and Feakle in its $27^{\text {th }}$ year during 2014); well-known within the folk world; and of around one week's duration. The Feakle festival is strongly associated with the East Clare traditional music style and with one of its key contemporary exponents, Martin Hayes. Precise attendance figures are not available, but it is estimated that the six day festival attracts audiences of 5,000-8,000 (Pepper 2015). While the festival programme contains concerts, it has a very strong emphasis on workshops and sessions that call for active participation on the part of festival attendees. The venues comprise four pubs, the community hall, primary school, parish church, a restaurant/hostel and outdoor / temporary venues. With a capacity of 25,000 people a day and over 700 events over the week, Sidmouth International 
Folk Week is one of the biggest folk festivals in the UK. The festival takes over the pubs, hotels, outdoor spaces and community halls of Sidmouth. Its events include concerts by top folk performers in the 1,000 seat temporary indoor stage, daily dance displays, and a torchlight procession, but like Feakle, it also has a very strong emphasis on active participation with an extensive programme of music and dance workshops, children's activities, open-mic and informal music and song sessions in the town's pubs.

A qualitative approach to data collection was used and a series of 'in-the-moment' interviews were carried out during the respective festival times in summer 2014 with an array of social actors including audiences, volunteers, festival organizers, local business people, performers, and those who try to avoid the festivals. The interviews were semi-structured in nature and averaged 15-20 minutes in duration. They were recorded and transcribed verbatim. This paper concentrates on reporting the data gathered from local people only. At Sidmouth Folk Week, a total of 37 interviews were carried out with local people, capturing the views of 39 local festival stakeholders. In Feakle, 29 local people were interviewed. With the exception of the festival committee who were interviewed indoors in a venue of their choosing, interviewing took place in public spaces, at varying times of the day and evening.

\section{Study findings}

The reported data clearly show that the festivals interrupt the normal workings of their places. As a Sidmouth respondent explained: 'It's just a very special atmosphere that the town's got. I mean if you live in Sidmouth you realise that it's a very different place during the festival compared to what it is for the rest of the year' (S37). The question remains as to what that means for the host societies and places.

\subsection{Temporal dimensions}


Echoing Foucault's claim that heterotopias are most often linked to slices in time (Foucault and Miskowiec, 1986), the findings most obviously relate to the festivals' temporal characteristics. In speaking about the festival, local interviewees were very likely to speak about its transformative effects in terms of time. Emphasising disruption, a Sidmouth local folk dancer (S46) explained: 'It's a huge onslaught of people for a very short period of time in a very small geographical location and it can get a bit much sometimes'; while another (S28) pragmatically said 'I just say it's one week. The one week of the year that we've got a bit of disruption. Enjoy it. If not stay away. Come back in a week, it's gone. No problem'. Transformations were similarly apparent to interviewees in Feakle where the liveliness, energy and 'buzz' engendered by the festival was unanimously welcomed:

'Oh it just brings so much life around Feakle because it's such a small and quiet village and then all of a sudden people everywhere, the atmosphere, what they bring to Feakle you know, it's just brilliant for everybody I think' (F13).

For local people in Feakle, the attraction of the festival in drawing them into their village to be with other local people was compelling, with interviewees reporting how villagers arranged holidays at this time so as to be around for the festival; and local people now living away from Feakle arranged to return to catch up with friends and family, also returning to the village specifically at this time.

There were numerous instances of how, in the transitory moment of the Feakle festival, routine notions of time seemed to be turned upside down: parents reported their children staying out late; security personnel patrolled the village at night; local shops opened late; people took time off work. The busyness created by the movements of people through the village embodied the festival's energy, and time assumed a different order: 'It's unbelievable for the place ... And I mean we find the minute it starts on the Wednesday night whatever, it's off on a tidal wave then' (F14).

In addition to highlighting these fleeting dimensions of time, the data show how the festivals serve to accumulate layers of time: collapsing age differences among festival goers and musicians; collating, 
remembering memories and stories; and reworking styles and tunes from different time periods. As interviewees talked, they effortlessly drew on their memories of past times and events while making observations on the present. In Feakle there was a sense that the festival embodies and encapsulates the musical memory of the East Clare area, gathering it together and offering it both to the uninitiated and to the long initiated for whom regular practice and appreciation may have lapsed. One local resident (F12), partaking in a fiddle workshop explained: 'I would have played it when I was younger. My daughter is learning it. I mean I would have grown up with it'. Equally, the data attests to the role of the festivals in reproducing engagement with the tradition and passing it on inter-generationally:

'And even from the youngest to the oldest you see them mixing, you see them chatting to the old folks openly, playing with them, intermingling with them in every way. So it's sort of something that has a magic of its own' (F6).

This function of the festivals was very powerfully felt and in both places, the profound sociability that it stimulated was articulated:

'You get people coming out, young and old. Quite often you'll come to a folk festival (like Sidmouth) to reunite with people that you used to, in your youth, go out with over folk week and that's pretty amazing 'cos you see people that you haven't seen for so many years and they always come back to folk week' (S40).

In Feakle, the injection of visitors, vastly outnumbering the local population, greatly alters the social make-up of the community: 'it brings people to the village. And there's an intercultural thing I suppose about it and it opens us ... And the community love the buzz of people. They love it' (F19).

\subsection{Spatial dimensions}


The spatial transformations were also very apparent. Festival heterotopias come into being as accumulatively, discrete spaces are transformed through the workings of the festival. In Feakle village the absence of a dedicated cultural infrastructure to house the festival means that every possible space is transformed from everyday usage to one replete with apparently contradictory meanings. Adults attend workshops in primary school classrooms, private houses become B\&Bs, publicans allow children attend music sessions, the school yard becomes an outdoor café, and the church altar becomes the stage for the main headline event. Similar transformations were effected in Sidmouth as the promenade, lined with temporary stalls, becomes the route for the procession and hosts the fireworks display. Spaces were altered in ways that were often distinctly at odds with the normal social order, and the transformations were very obvious to study participants: 'It uses a lot of spaces that aren't utilised to their potential the rest of the year, that's for sure. Like this garden we're sat in now' (S40);

'It's nice to see all the gardens and the fields as well which aren't, they're normally just green with a few clouds, as you're coming into town you see all the campers and the streamers out and it's very nice and the ribbons around tree trunks, it's rather nice I think' (S8).

Cumulatively, the transformation of many discrete spaces transforms the two study places into counter-sites, a term that Foucault used to refer to 'unsettling or ambiguous social spaces' (St John, 2001: 51). At times, this led to disquiet, particularly in Sidmouth, where tensions arose in the multiple recasting of places like the aforementioned promenade, as different actors, including buskers, stallholders, residents and shoppers competed to use it in different ways. The large influx of visitors arriving for the two festivals was a key transformative feature. This was controversial at times, with the occasional local resident in Feakle, for example, putting parking cones outside their house to obstruct parking. In the main, however, the influx that included numerous repeat visitors, was welcomed by the local populations who were familiar with regular festival-goers, as one Feakle 
resident explained: 'you'd know the minute it starts, (because) next thing is you see somebody walking down the road and you'd say, such and such a person is here already, he's back already' (F1).

Intensified social relations were a key part of the social contexts engendered by the space-time of the festivals. In Sidmouth, many local interviewees reported that their use of spaces for socializing changes during Folk Week, either their use of existing cafes and restaurants intensifies, or they make use of the specially constructed festival facilities which appear on the green spaces of the town. The conversion of the usually unoccupied green spaces of the town into festival spaces and the provision of focal entertainment sites helped to facilitate more social interaction than usual. Local interviewees reported seeing more of friends from the locality and from further afield and of making use of the festival hub where there was a buzz: 'But yeh, I mean socially it's a wonderful thing to be able to say to our friends oh yeh we'll meet up there and ... You get involved in that normally' (S6).

'People always make sure they go out festival week, if you haven't gone out in Feakle for months or weeks you know you'll say look I'll go down some night of the festival because you'll meet loads of people so that's for the locals' (F12). Amidst these heightened social relations, the potential for reinvigoration and renewal is ever-present not only for collective local socialization but also for visitors for whom folk festivals can: 'become a religion, it's kind of one of the Meccas' (F15). 'I think that this festival is a very important one that brings people from all over the world really. I think the source is very important...... And when people come from outside the area ... they are looking for something that is authentic, something that's deep and meaningful and soulful' (F10).

\subsection{Rites of entry and barriers to inclusion}

However, a defining feature of heterotopias is that they 'presuppose a system of opening and closing that both isolates them and makes them penetrable' (Foucault and Miskowiec, 1986: 26) and so it was in the two festival sites. Everywhere, signs and symbols, such as the displays in the windows of charity 
shops, bunting on the streets, traffic diversion signs, and billboards advertising gigs, signified that the festivals were 'open'. Advance preparations, ritually undertaken every year in Feakle, even involved local householders painting their garden walls. In Sidmouth, local interviewees were very aware of the effect the festivals had on their town: 'You can tell they all kind of prepare for the festival - they put all colourful folky clothes up in the windows' (S25). Access to the festival emplacement was experienced in degrees. Participation through spectating and attending free open-air events was open to all, and people experiencing the festival in these capacities seem to fully embrace the excitement, sociability and pleasure that this afforded. However, as already explained, both of these festivals' programmes were hugely encouraging of active participation in workshops, sessions and open-mic events, and it seemed universally understood that participation as an artistic performer required certain distinctions. Possessing artistic knowledge and ability, and having an acknowledged reputation for same, were prerequisites that effectively controlled degrees of participation. These controls filtered through the different layers of performance possibilities, from internationally renowned professional, through various levels of amateur proficiency. Interview data showed that the desirability for acceptance into the festival emplacement was very strong, and acted as a keen motivator for aspiring musicians to improve and gain access in future. Among amateurs in Sidmouth, not having the courage to fully join in due to a perception of not knowing the right songs or not playing a recognised folk instrument was mentioned as a 'gesture' which some were unable to make to gain entry. In both places, a number of amateurs showed an understanding that they could not partake because they 'wouldn't be at that standard' and that in order to fully gain entry they needed to apply themselves some more. An invitation to perform at Feakle is highly prized. As F10 explained:

'If you were to look at the Feakle festival from an international perspective, I know people within the musical community involved in Irish music that would see it as being very important to visit or to be acknowledged ..... Yeah, I think that they would see it as an endorsement or an acknowledgement'. 
Being invited to perform at Feakle carries a distinction that must be earned, and the Festival Directors act as gatekeepers determining who among the throng may gain access. When asked whether there was any problem sourcing musicians for the festival one of the Directors explained: 'Oh no, they want to come ... in fact I went into a music session one night there, Wednesday night and before I left I had three CDs handed to me from three different combinations' (F1).

The data uncovered a number of unspoken rules determining entry: in Sidmouth, local amateurs who had participated in the past spoke about having lost their ability to take part because of the physical ailments of later life. Respondents talked of not being able to sing or play instruments as proficiently as they used to, and of being less confident and less physically able to take part as they did in the past. Others explained that participation was also influenced by being part of a local network, such as gaining a performance slot in the open mic programme in Sidmouth by being part of a local folk club, as S32 highlighted: 'We run a club here once a month and then anybody who plays at the club, if they want to have a half-hour slot in the Folk Week, then we give them a half-hour slot.'

\subsection{Relation to other spaces}

Heterotopias only exist, and can only be made sense of, in relation to the ordinary, routine spaces and times alongside which they exist. Foucault suggested that heterotopias have a mirroring effect, and offer the possibility for self-reflection, both at the individual and broader societal level. Here, the intense experience offered by the festivals brought aspiring artists' self-perceived shortcomings into focus and encouraged them to reflect on their abilities: 'it's more self-conscious I guess during the festival time' (F36). At the personal level, for artists there were opportunities to learn from experts, to advance one's skills, repertoire, contacts, etc. and to immerse oneself in the artistic communitas engendered temporarily in these places. From a social interaction perspective, buoyed by the liveliness, and heightened atmosphere of the festival time-space, there were opportunities for all present to regroup, refresh and bond with family, friends and strangers alike. For locals, there was also 
the opportunity to challenge oneself, as well as the stasis of everyday lifestyles, by becoming actively involved in organizing the festival, hosting visitors, preparing stages, managing the sites, etc. and there were ample data showing that individuals grasped these chances. More broadly there was also a sense in which the counter-site nature of these festivals enabled local communities to experiment with different ways of social order as, for example, 'ordinary' people assumed leadership roles; and powerful institutions like the Catholic church allowed their premises be transformed into a commercial venue. Equally, it encouraged them to temporarily extend themselves by taking on extra workloads, re-ordering public spaces to house the festivals and accommodating hundreds of visitors in private spaces. In the process, individually and collectively, people were seeking to achieve more potential, and aspire towards a more ideal state for themselves, their communities and their places. As one local woman explained when commenting on how spaces within Feakle:

'Oh that's part of the community, that's how community evolves. A school isn't just particularly for the education of children Monday to Friday, this is actually a facility within the community that should be used. Same as the church, same as the community center and then the pubs.... they also allow their premises to be used for sessions and as a facility again, so it all contributes to the community. And also I think people open their homes and their houses to keeping visitors and again that's good' (F11).

For the community of folk musicians who congregate annually in Feakle, the very public showcasing that the festival affords their art form is profoundly important. As F8 explained:

'It's good to see other people do it, ... it's almost like saying okay I'm not alone trying to do this ... And to see it presented is a big deal because you can always sit and do it in some little corner and never get any approval for it'. More generally in Feakle, there was an understanding that the festival brought external validation for the area's living musical heritage. F17 put it very succinctly: 'It's like the old story, a man is never famous in his own land. He had to go away to make his name and then come back and be famous'. Local interviewees tended to understand this and to recognise the significance 
of the festival both in highlighting the folk music tradition and in revealing the cultural underpinnings of the village itself:

'The festival ... it's an outside recognition of what's happening here through the year.... It's like looking in a mirror; you need to see yourself reflected back by a different source sometimes. .... And like there were a lot of musicians around here going back to the .... 60 s and 70 s who were playing music away, .... no status at all, no recognition and even looked down on socially you know, .... so the festival has accorded status to the local tradition' (F16).

Most recently, this is now epitomised in the local traditional music superstar, Martin Hayes. As F3 explained: 'and of course the big secret I think as well is Martin Hayes is from Feakle'.... I think we nearly took him for granted until we saw how big he's got'. This external validation generated by the festival fuels a local consciousness of the importance of local heritage. As a local musician explained:

'I think it keeps alive a kind of sense of identity here. I mean like this part of the world is known for its musical heritage as well. I think that keeps that live.... builds a sense of local pride as well, makes them feel they are not in some outpost here but at the center of something as well and this area .... has some resonance beyond the locality'.

\section{Analysis}

The work of all of the theorists discussed in section 1 of this paper has been formative in shaping interpretations of how festivals effect spatial and temporal transformations. However, a shortcoming of this work is that it lacks an overarching theoretical framework both to adequately encase the diverse concepts employed and to facilitate an appreciation of the inter-twining roles of time and space. Furthermore, much of the empirical data marshalled in the literature relates to urban festivals. In contrast, the study reported here locates its empirical enquiries in small settlement contexts and argues that Foucault's heterotopia concept has much potential for providing a useful means of understanding how social meanings are constantly reproduced and represented through festivals, and 
of revealing how festivals hosted in small scale settlements strongly inform the identity and representation of rural places. Leaving aside the first two principles of heterotopia, due to their macro scale, as highlighted earlier, a number of key points have emerged from the data relating to principles three to six. Following discussion of these four principles, a modified and elaborated elucidation of the concept is proposed.

\subsection{Principle 3: Heterotopias juxtapose several incompatible sites within a real space}

Foucault's first principle, that several incompatible sites are juxtaposed within a heterotopia, certainly held true. Because the study festivals happened within the host places (as opposed to on external greenfield sites), and because their scale was such that they dominated their host areas, the degree of spatial transformation was very obvious. Multiple spaces, public, semi-private and even private in nature, were transformed in ways that challenged the normal social order, disrupted routine understandings and altered standard uses, sometimes to controversial effect. This was evident in the data showing how interviewees experienced and made sense of the changes. Similar kinds of spatial transformations are well recorded in the literature, however less understood is the accumulative effect of all of these spatial alterations. Foucault and Miskowiec (1986) identify the traditional gardens of the Persians, dating from around a thousand years ago, as the oldest examples of heterotopias. They explained that these gardens were regarded as sacred spaces which brought together the four parts of the world into a microcosm with the umbilicus-like fountain at the centre being seen as having still further heightened sacredness. In line with this analogy of the garden as heterotopia, an overall effect of the spatial transformations evident here, especially in the Feakle case, was to turn the village into something of a sacred space upon which festival attendees converge in what might be described as a rite of pilgrimage. For Nelson (2006: 8), sacred spaces are bound up with identity and a shared sense of belonging: 'being there serves to connect you with others who have a shared system of belief', and reminds people that they belong in a body of social relationships (Chidester \& Linenthal 1995). Being part of this set of shared relationships was evident to study participants. A musician, for 
example, explained: 'people who are likeminded and share a repertoire or share emotions or feelings are drawn to this place, so that's one of the things. The other thing is that there's great listeners here' (F 22). So too did a local publican: '... they have workshops with some of the finest musicians in the country if not in the world. So they have that, and what they get from that is I suppose motivation to continue on' (F12).

Like the umbilicus in Foucault's garden example (Foucault and Miskowiec, 1986), the transformed village, as festival counter-site, functions as a source of sustenance or nourishment, re-energizing and revitalizing those who come to express their shared sense of belonging, thereby fortifying their ability to return to routine lifestyles. As Falassi (1987: 3) argued, an important role played by festivals is 'to renew periodically the life stream of a community by creating new energy and to give sanction to its institutions'. The possibilities for renewal facilitated by the altered spatial ordering were rooted in the artistic practices that underpinned the celebrations, but they also lay in the heightened sociability that seemed widespread. The data reveal a great deal of social bonding among cohorts of festival actors including: performing artists, extended families, groups of friends, long-standing repeat visitors, and between the latter group and local people. The conversion and opening up of existing spaces (e.g. school yard turned open air café, promenade turned procession route) and the compression of so many people into these spaces promoted an atmosphere that inspired intense and varied social interactions.

\subsection{Principle 4: Heterotopias break or disrupt traditional concepts of time by interrupting} present time and accumulating past times.

The understanding that festival time differs from ordinary, routine social time is well established in the literature and is a defining feature of Foucault's concept. The data reported here attest to how interviewees strongly understand that the festivals changed their town / village. That the festivals 
interrupted time in this way, every year, had come to be recognised as the natural order and it was acknowledged, welcomed or at least tolerated as such. However, in line with the sociological writings on carnival (Bakhtin, 1968), it was equally well understood that the transformations were only transitory.

Yet, Foucault also saw within heterotopia the ability for time, even when transitory, to accumulate and capture layers of different time periods in one 'moment'. This was apparent in the data in a number of ways. Most obviously, the study festivals accommodated and transmitted the very dynamic processes central to the artistic practices upon which they were ostensibly focused. Processes of: initiation, listening, learning, remembering, passing on traditions, experimenting, improvising, etc. all depended on the intertwining of time. The data clearly show this to be case, as interviewees in one breath talked about their earlier festival experiences, their younger efforts to play an instrument, their memories of older performers, older tunes, techniques or styles, and their hopes to play more proficiently in the future. In part, the festivals achieved this through the inter-generational interaction that was a noted feature of the heightened sociability discussed above. Again, some of this had been fostered by the workings of the festivals over time, as musicians returning over the years re-connected with other musicians whom they had previously met here; as repeat visitors socialised with other visitors on their annual 'pilgrimage' to the festival and as they once again met local people in B\&Bs, shops and pubs. When additionally viewed as accumulated time, the social function of festivals assumes a new significance.

While Foucault's understanding of heterotopia as accumulated time has been acknowledged in a festival context previously (Howell, 2013), it is under-researched. These findings recommend it as a very useful tool of analysis, especially in respect of how folk festivals inform constructions of rurality. As Gibson and Davidson (2004) suggest, folk music in rural locales often reference popular mythology and nostalgia for the past. However, the analysis presented here reveals how, far from being static or unchanging, folk music is continuously reinvented and re-worked as it is transmitted through the 
vehicle of the festival. In the process, the representation of rural places and the construction of identity through music, as well as the ways in which people connect and emotionally engage with places through music are continuously being reproduced.

\subsection{Principle 5: Heterotopias require certain acts or performances both to gain entry and to} sustain participation therein.

Echoing the features of rites of passage, Foucault's fifth principle of heterotopia suggests that they have a system of opening and closing. Most obvious in the data presented here were the signs and symbols signifying that the festival, as heterotopia, was, in the first instance, open. The interviewees told of an array of preparations undertaken for the transformation that was to be effected: painting front walls, putting up bunting, etc. These preparations created a sense of welcome, and played a part in signaling the ritual transformation of space. Some of these signs illustrated Foucault's argument that while heterotopias function as counter-sites with a different social order, they are far from being free of social control. So, for example, the traffic restrictions, no parking signs and one-way systems which privileged certain flows within the emplacement, simultaneously curtailed others. Thus, although in theory anyone can enter, Foucault claims that gaining full entrance is premised on acquiring certain permissions and performing certain gestures. This claim was strongly supported here, with degrees of inclusions and exclusions clearly evident based on, for example, artistic knowledge, artistic proficiency, relationship with gatekeepers, commercial reputation and historical connections with festival. In response, interviewees showed themselves to be variously resigned, accepting, motivated, irritated or confrontational. This particular principle strongly resonates with the argument that festivals are never 'impromptu or improvised...and arts festivals in particular, are never spontaneous' (Waterman, 1998: 59). It also underpins the well accepted idea that 'particular sets of meanings reproduced through events are open to challenge, contestation and disruption from those who disagree or think differently' (Quinn, 2009: 500). 
Importantly, the data illustrate the dynamic nature of heterotopias. Inclusion is fluid, with full acceptance being premised on the ability to continue 'making the grade'. Here interviewee responses clearly showed an understanding that one can lose the right to inclusion if one is no longer able to meet the required approval (e.g. stiff fingers mean a declining ability to play a wind instrument); equally, the data showed people aspiring to, and envisaging moving closer to, the center of the 'sacred space', once they managed to raise their proficiency. This suggests a further potential for stretching Foucault's concept to deepen its applicability to festival settings. It is not just the points of entry that are important. It matters also how people act once inside the heterotopia: whether, and how, they continue to respect the necessary rites and perform the required gestures. In the intensity of the festival time-space, it may be that festival actors, whether it be a clerical worker turned festival manager, full-time home-maker turned B\&B entrepreneur, aspiring amateur turned temporary professional, become more immersed in their altered or extended roles. What this means individually and collectively, in the moment of the heterotopia and in the context of ordinary social time seems worthy of much further investigation, especially in rural settings where annual festivals can be something of a life blood, both economically and socially. Here, the data revealed both the personal efforts made, and the rewards accrued, as some local people got involved in festival roles. The latter included acquiring self-confidence, learning managerial skills, adapting to commercial contexts and developing social networks.

\subsection{Principle 6: Heterotopias have a function in relation to all other space}

Foucault's final principle, that heterotopias have a function relative to all other space and can only be fully understood once viewed in this light is very much under-developed in festival research. Its applicability in festival research has been illustrated in a number of ways in this study. Firstly, as a reminder that 'festivals must negotiate a 'placement' for themselves with the historical and ideological flows that run within and through the city' (Falconi, 2011: 9), it helps advance understandings of how certain heterotopia arise when and where they do. Here, the data yielded insight into the complicated, 
historically embedded relationships that link cultural heritage, place and cultural festivals in rural settings.

Emerging most strongly from the data was the idea that the altered time-space of the heterotopia, like mirrors, enable people to see reflections of themselves, their social worlds and their places. Very obviously, the festivals acted as a strong reminder, for locals and visitors, of the long standing musical heritage that the two places have developed. While this musical heritage lay at the core of the two festivals, it was intimately bound up with other socially constructed notions of what lies at the heart of these rural places: 'something that's genuine', 'like stepping back in time a bit', 'closely knit', 'friendly and open', 'encompasses who we are in rural Ireland'. Repeatedly, descriptors like these showed how respondents understood the festivals to capture what these places, more generally, mean to them. At the personal level, the data also showed much evidence of self-reflection with locals and visitors, in the guise of performing artists, audiences, volunteers and organizers alike, reflecting on themselves and striving for something other, in the temporary setting of the festival. Individually and also collectively, there were concerted efforts to re-ignite, reinvigorate and renew memories and traditions, abilities and capacities, as well as social connections that ranged from the intimate through extended family and friendship groups and beyond. In the process could be seen a collective effort to challenge the shortcomings of the normally prevailing social order, to view afresh the potential of local space and to bring it closer to what might be considered its ideal state. While Vijay (2015), writing about the Olympic Games, is highly critical of the kinds of possibilities associated with the temporary Games, the findings here echo the sense of potentialities that Shields (2003) and Pløger (2010) have associated with temporary festivity. Could it be that a place sometimes works best when it is outside of routine, such that social actors have the opportunity to find new ways of challenging the status quo, re-working the social order and re-making place in line with local needs? The 'more ideal' state achieved is transitory by definition. Were it to be allowed to continue it could contravene too many societal rules and in the long-term, could cause chaos, by e.g. encouraging children to be in pubs, and having school premises open to strangers. But in that brief moment, as the intensification of social 
relations engendered by the festival goes into over-drive, the accumulative transformation of festival spaces creates a different yet similar, new yet traditional, festival place that temporarily dislodges the ordinary place.

If these processes could be said to be strongly rooted in a local context, they were strongly underpinned by the fact that as well as reflecting inwards, festival spaces also reflect outwards, displaying cultural activities and social norms to the world more broadly. Here the effect of external flows of affirmation could be seen to be validating and strengthening the processes of renewal evidently at play. This was apparent not only in the artistic productions but also in the social relations among and between cohorts of audiences, performers, volunteers of various kinds and gatekeepers. The data thus support calls from researchers like Fox Gotham (2005: 323) who urged researchers to 'develop our understanding of how places and extra-local flows constitute each other, rather than seeing them as opposing principles'.

\section{Conclusion}

The study reported here has found the theoretical concept of heterotopia to be a valuable framework for examining how festivals transform the prevailing social order within rural contexts. Interpreting the findings in light of the concept has revealed important insights into the social and spatial dynamics of festivals and into the historically embedded nature of rural living more broadly. After reviewing the literature and analyzing the empirical data, the authors suggest that a slightly modified framework is worth developing. In this respect, Foucault's first two principles were set aside, as while they certainly have application for rural studies, their emphasis on the macro scale requires a more longitudinal line of enquiry. Instead, the modified framework focuses on the four remaining principles, highlighting aspects that could be usefully elaborated in further research. The proposed new principles of festivals as heterotopia within small-scale settlements are outlined in Table 1.

Principle 1

Festival heterotopias juxtapose several incompatible sites within a real space 


\begin{tabular}{|l|l|}
\hline Principle 2 & $\begin{array}{l}\text { Festival heterotopias break or disrupt traditional concepts of time by } \\
\text { interrupting present time and intertwining layers of past time }\end{array}$ \\
\hline Principle 3 & $\begin{array}{l}\text { Festival heterotopias require certain acts or performances to gain entry and to } \\
\text { sustain participation therein }\end{array}$ \\
\hline Principle 4 & Festival heterotopias exist only in relation to all other sites and spaces \\
\hline
\end{tabular}

Table 1: Four principles of festivals as heterotopias within small-scale settlements.

Foucault's argument that heterotopias juxtapose several incompatible sites is very well empirically supported in the festival literature. However, the accumulative effect produced through the transformation of multiple discrete spaces is less well understood and requires further enquiry. Here, the findings highlight an accumulative transformative effect, although they show that it can differ: quite cohesive, uniform and positive as in Feakle; more fractured, contentious and uneven as in Sidmouth. The argument that heterotopia break or disrupt traditional concepts of time has been shown to be very important but the temporal dimension could be further developed in order to understand the temporal layering effect of festivals: that is, a sense of past festivals intertwining with and informing the social actors' experience of current festivals. For rural studies more generally, the merit of heterotopia as an analytical tool lies in its ability to open up the multiple layers of rurality revealed through the workings of the festivals, and to expose their changing, dynamic and sometimes contested nature. The contention that heterotopias may require certain acts, performances or rituals to gain entry and sustain participation is also instructive in that it points to the fluid, and multi-faceted ways through which people engage with festivals and by extension with the places where festivals are held. The two case studies in this paper are both folk festivals, a genre known for its emphasis on participation in music and dance. Further research is recommended to investigate what the participative nature of these festivals means in terms of what motivates people to attend, how they 
engage, and what meanings they attach to their participation. Equally, further research is needed to investigate whether certain acts and performances are needed to gain entry, and sustain participation in, other types of festivals where this may not be the case. Finally, the question as to whether the conclusions drawn here could apply to contexts beyond the rural and to other geographical scales is another potentially interesting avenue for future research enquiry.

\section{References}

Authors, 2016. Linking social capital, cultural capital and heterotopia at the folk festival. The Journal of Comparative Research in Anthropology and Sociology (COMPASO), 7, 23-39.

Abrahams, R.D., 1982. The language of festivals: celebrating the economy, in: Turner, V. (Ed.), Celebration: studies in festivity and ritual. Smithsonian Institution Press, Washington, D.C., pp. 161177.

Bakhtin, M., 1968. Rabelais and his world. Massachusetts Institute of Technology, Cambridge, Mas. and London.

Brennan-Horley, C., Connell, J., Gibson, C., 2007. The Parkes Elvis Revival Festival: economic development and contested place identities in rural Australia. Geographical Research 45, 71-84.

Chidester, D., Linenthal, E. T. 1995. (Eds) American Sacred Space. Bloomington and Indianapolis, Indiana University Press.

Connell, J., Gibson, C., 2011. Elvis in the country: transforming place in rural Australia, in: Gibson, C., Connell, J. (Eds.), Festival places: revitalising rural Australia. Channel View Publications, Bristol, pp. 175-193.

Curtis, R., 2011. What is Wangaratta to jazz? The (re)creation of place, music and community at the Wangaratta Jazz Festival, in: Gibson, C., Connell, J. (Eds.), Festival places: revitalising rural Australia. Channel View Publications, Bristol, pp. 280-293. 
Duffy, M., Waitt, G., 2011. Rural festivals and processes of belonging, in: Gibson, C., Connell, J. (Eds.), Festival places: revitalising rural Australia. Channel View Publications, Bristol, pp. 44-57.

Duvignaud, J., 1976. Festivals: a sociological approach. Cultures 3, 13-25.

Eagleton, T., 1981. Walter Benjamin: towards a revolutionary criticism. Verson, London.

Falassi, A., 1987. Festival: definition and morphology, in: Falassi, A. (Ed.), Time out of time: essays on the festival. The University of New Mexico Press, Alburquerque, pp. 1-10.

Falconi, J.P., 2011. Spaces and festivalscapes. Platform, Communities and Performance 5, 5-18.

Falconi, J.P., 2014. The Festivals Internacional de Teatro de la Habena (FITH) and the Festival of Mexico (fmx): between place and placelessness. Latin American Theatre Review 48, 181-193.

Foucault, M., 1984. Des espaces autres. Une conference inedite de Michel Foucault. Architecture/Mouvement/Continuite 5, 46-49.

Foucault, M., 1986. Of other spaces, trans. D'Almeida, L. Evans, H, Ortelli, L. Sadleir, R. and Sancristoforo, G. Lotus 48, 9-17.

Foucault, M., 1997. Different spaces, trans. Robert Hurley, in: Faubion, J. (Ed.), Essential works of Foucault 1954-1984, Volume ii: Aesthetics, method and epistomology. Penguin Books, London, pp. 175-186.

Foucault, M., 2008. Of other spaces (1967), trans. De Cauter, L. and Dehaene, M., in: Dehaene, M., De Cauter, L. (Eds.), Heterotopia and the city: public space in a postcivil society. Routledge, Abingdon, pp. 13-29.

Foucault, M., Miskowiec, J., 1986. Of other spaces. Diacritics 16, 22-27.

Fox Gotham, K., 2005. Tourism from above and below: globalization, localization and New Orlean's Mardi Gras. International Journal of Urban and Regional Research 29, 309-326. 
Gallup, S., 1988. A history of the Salzburg Festival. Weidenfeld and Nicolson, London.

Gibson, C., Connell, J., Waitt, G., Walmsley, B., 2011. The extent and significance of rural festivals, in: Gibson, C., Connell, J. (Eds.), Festival places: revitalising rural Australia. Channel View Publications, Bristol, pp. 3-24.

Gibson, C., Davidson, D., 2004. Tamworth, Australia's 'country music capital': place marketing, rurality, and resident reactions. Journal of Rural Studies 20, 387-405.

Hetherington, K., 1997. The badlands of modernity: heterotopia and social ordering. Routledge, Abingdon.

Howell, F.C., 2013. Sense of place, heterotopia, and community: performing land and folding time in the Badalisc Festival of Northern Italy. Folklore 124, 45-63.

Jackson, P., 1988. Street life: the politics of carnival. Environment and Planning D: Society and Space $6,213-227$.

Johansson, M., Kociatkiewicz, J., 2011. City festivals: creativity and control in staged urban experiences. European Urban and Regional Studies 18, 392-405.

Johnson, P., 2013. The geographies of heterotopia. Geography Compass 7, 790-803.

Karaosmanoglu, D., 2010. Nostalgic spaces of consumption and heterotopia: Ramadan festivities in Istanbul. Culture Unbound 2, 283-302.

Kong, L. 1995. Popular music in geographical analysis. Progress in Human Geography 19, 183-198.

Lefebvre, H., 1991. Critique of everyday life, 2nd ed. Verso, London.

Maffesoli, M., 1996. The time of the tribes: the decline of individualism in mass society. Sage, London.

Nelson, L. P. 2006. (Ed) American Sanctuary: Understanding Sacred Spaces. Bloomington and Indianapolis, Indiana University Press. 
Nettl, B., Capwell, C., Bohlman, P., Wong, I., Turinon, T. 1992. Excursions in world music. New Jersey, Prentice Hall.

Olsen, C.S., 2012. Re-thinking festivals: a comparative study of the integration/marginalization of arts festivals in the urban regimes of Manchester, Copenhagen and Vienna. International Journal of Cultural Policy 19, 481-500.

Pepper, G. 2015. Personal Interview, January 2015.

Pløger, J., 2010. Presence-experiences: the eventalisation of city space. Environment and Planning: Society and Space $28,848-866$.

Quang, N.N., Wildemeersch, D., Masschelein, J., 2013. Community forests as heterotopia. The case of the Mu community forest - Ngoc Son - Ngo Luong Nature Reserve, Vietnam. International Journal of Environmental Studies 70, 877-892.

Quinn, B., 2005. Changing festival places: insights from Galway. Social and Cultural Geography 6, 237252.

Quinn, B., 2009. Festivals, events and tourism, in: Jamal, T., Robinson, M. (Eds.), The Sage Handbook of Tourism Studies. Sage, London, pp. 483-503.

Rihova, I., 2013. Book review: music festivals and regional development in Australia. Annals of Tourism Research 36, 119

Rofe, M.W., Winchester, H.P.-M., 2011. Marketing a sustainable rural utopia: the evolution of a community festival, in: Gibson, C., Connell, J. (Eds.), Festival places: revitalising rural Australia. Channel View Publications, Bristol, pp. 194-208.

St John, G., 2001. Alternative cultural heterotopia and the liminoid body: beyond Turner at ConFest. The Australian Journal of Anthropology 12, 47-66. 
Saldanha, A., 2008. Heterotopia and structuralism. Environment and Planning A 40, 2080-2096.

Shields, R., 2003. The virtual. Routledge, London.

Smith, S. J. 1997. Beyond geography's visible worlds: a cultural politics of music. Progress in Human Geography 21, 502-529.

Stanciu, E.-L., 2014. Urban space and queer identities: the LGBTQ Film Festival as heterotopia. Analize - Journal of Gender and Feminist Studies, 159-177.

Stevens, Q., Shin, H., 2012. Urban festivals and local social space. Planning Practice \& Research 29, 120.

Turner, V., 1982a. From ritual to theatre: the human seriousness of play. PAJ Publications, New York.

Turner, V., 1982b. Introduction, in: Turner, V. (Ed.), Celebration: studies in festivity and ritual. Smithsonian Institution Press, Washington, D.C., pp. 11-32.

Van Gennep, A., 1960. The rites of passage. Chicago University Press, Chicago, IL.

Vijay, A., 2015. After the pop-up games: London's never-ending regeneration. Environment and Planning D: Society and Space 25, 425-443.

Waterman, S., 1998. Carnivals for elites? The cultural politics of arts festivals. Progress in Human Geography 22, 54-74.

Weller, S., 2013. Consuming the city: public fashion festivals and the participatory economies of urban spaces in Melbourne, Australia. Urban Studies. 50, 2853-2868.

Yarwood, R., Charlton, C. 2009. Rurality, folk music and 'Show of Hands'. Journal of Rural Studies 25, 194-206.

Yazbak, M., 2011. The Muslim Festival of Nabi Rubin in Palestine: From Religious Festival to Summer Resort. Holy Land Studies: A Multidisciplinary Journal (Edinburgh University Press) 10, 169-198. 
